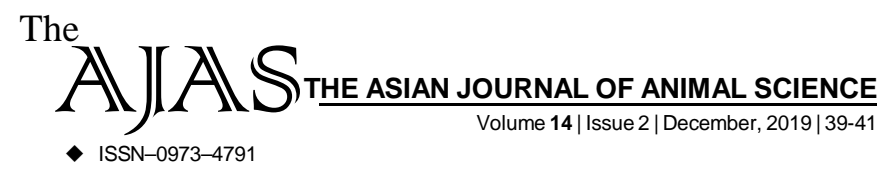

\title{
Sensory quality of Kheer prepared by using aromatic varieties of rice
}

D.M. Choudhari and V. S. Kadam

Author for Corresponding -

D.M. Choudhari Animal Husbandry and Dairy Science, Krishi Vigyan Kendra, Dhule (M.S.) India

Email: balrajdairy_2007@

rediffmail.com
ABSTRACT...... Kheer was prepared by boiling presoaked aromatic rice in concentrated milk (partial dehydration of whole milk) till cooking which was sweetened by the sugar.The different aromatic verities of rice had a definite effect on physical quality of Kheer and also increasing the overall acceptability of Kheer. Out of aromatic rice varieties used in experiment the Basmati, Sakoli-7 and Makarand obtained like moderately.

KEY WORDS...... Milk, Aromatic rice, Kheer

HOW TO CITE THIS ARTICLE - Choudhari, D.M. and Kadam, V. S. (2019). Sensory quality of Kheer prepared by using aromatic varieties of rice. Asian J. Animal Sci., 14(2): 39-41. DOI : 10.15740/HAS/ TAJAS/14.2/39-41. Copyright@ 2019: HindAgri-Horticultural Society.

ARTICLE CHRONICLE - Received : 07.08.2019; Revised : 25.11.2019; Accepted : 27.11.2019 